\title{
The Impact of the COVID-19 Pandemic on Depression and Sexual Function: Are Pregnant Women Affected More Adversely?
}

\section{O impacto da pandemia de COVID-19 na depressão e na função sexual: as mulheres grávidas são afetadas de forma mais adversa?}

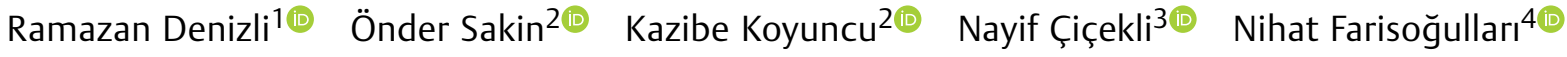 \\ Mikail Özdemir ${ }^{5}$
}

${ }^{1}$ Department of Gynecology, Arhavi State Hospital, Artvin, Turkey

Address for correspondence Ramazan Denizli, Boğaziçi Mah. Arhavi

2 Department of Gynecology, Kartal Dr. Lutfi Kirdar City Hospital, Devlet Hastanesi. Arhavi, Artvin, Turkey Istanbul, Turkey (e-mail: dr.ramazn@hotmail.com).

3 Department of Gynecology, Mus State Hospital, Mus, Turkey

${ }^{4}$ Department of Gynecology, Viransehir State Hospital, Sanliurfa, Turkey

${ }^{5}$ Department of Public Health, Marmara University School of

Medicine, Istanbul, Turkey

Rev Bras Ginecol Obstet 2021;43(10):765-774.

\begin{abstract}
Objective To investigate depression and sexual function among pregnant and nonpregnant women throughout the COVID-19 pandemic.

Methods A total of 188 women, 96 pregnant and 92 non-pregnant were included. The Beck Depression Inventory (BDI) and the Arizona Sexual Experience Scale (ASEX) were applied to the participants after obtaining sociodemographic data.

Results The depression scores of pregnant and non-pregnant women were similar $(p=0.846)$. We found that the depression scores were significantly higher among the group of participants who have lower economic status $(p=0.046)$. Moreover, the depression score was significantly higher among women who lost their income during the pandemic $(p=0.027)$. The score on the ASEX was significantly higher, and sexual dysfunction was more prevalent among women who have lower levels of schooling and income $(p<0.05)$. Likewise, the ASEX scores were significantly higher $(p=0.019)$

Keywords

- COVID-19

- pandemic

- pregnant

- depression

- sexual function among the group who experienced greater income loss throughout the pandemic. Upon comparing the pregnant and non-pregnant groups, we detected that sexual dysfunction had a significantly higher rate among pregnant women $(p<0.001)$. Conclusion In times of global crisis, such as the current pandemic, low-income families have an increased risk of experiencing depression and sexual dysfunction. When we compared pregnant women with non-pregnant women, depression scores were similar, but pregnant women were at a 6.2 times higher risk of developing sexual dysfunction.
\end{abstract}

received

November 3, 2020

accepted

August 8, 2021
DOI https://doi.org/

10.1055/s-0041-1736174. ISSN 0100-7203. (c) 2021. Federação Brasileira de Ginecologia e Obstetrícia. All rights reserved.

This is an open access article published by Thieme under the terms of the Creative Commons Attribution License, permitting unrestricted use, distribution, and reproduction so long as the original work is properly cited. (https://creativecommons.org/licenses/by/4.0/)

Thieme Revinter Publicações Ltda., Rua do Matoso 170, Rio de Janeiro, RJ, CEP 20270-135, Brazil 


\section{Resumo}

\section{Palavras-chave}

- Covid-19

- pandemia

- grávida

- depressão

- função sexual
Objetivo Investigar a depressão e as funções sexuais de mulheres grávidas e não grávidas durante a pandemia de Covid-19.

Métodos Um total de 188 mulheres, 96 grávidas e 92 não grávidas, foram incluídas. 0 Inventário de Depressão de Beck (Beck Depression Inventory, BDI, em inglês) e a Escala de Experiências Sexuais do Arizona (Arizona Sexual Experience Scale, ASEX, em inglês) foram aplicados aos participantes após a obtenção dos dados sociodemográficos.

Resultados As pontuações de depressão de mulheres grávidas e não grávidas foram semelhantes $(p=0,846)$. Verificou-se que as pontuações de depressão foram significativamente maiores no grupo de participantes de menor nível econômico $(p=0,046)$. Além disso, a pontuação de depressão foi significativamente maior em mulheres que perderam sua renda durante a pandemia $(p=0,027)$. A pontuação na ASEX foi significativamente maior, e a disfunção sexual foi mais prevalente em pessoas com menores escolaridade e nível de renda $(p<0,05)$. Da mesma forma, as pontuações na ASEX foram significativamente mais altas $(p=0,019)$ no grupo que experimentou maior perda de renda durante a pandemia. Ao comparar os grupos de gestantes e não gestantes, detectou-se que a disfunção sexual apresentava índice significativamente maior entre as gestantes $(p<0,001)$.

Conclusão Em tempos de crise global, como a atual pandemia, famílias de baixa renda têm um risco maior de sofrer depressão e disfunção sexual. Quando comparamos mulheres grávidas e mulheres não grávidas, as pontuações de depressão foram semelhantes, mas as mulheres grávidas apresentaram um risco 6,2 vezes maior de desenvolver disfunção sexual.

\section{Introduction}

Caused by the severe acute respiratory syndrome coronavirus 2 (SARS-CoV2), coronavirus disease 2019 (COVID-19) began with the first suspicious cases in November 2019 in Wuhan, Hubei, China, in late December. After that, the disease shortly spread throughout the world, in about three months. It was declared a pandemic by the World Health Organization (WHO) on March 12, 2020, and the first case in Turkey was reported on March 11, 2020. ${ }^{1,2}$ The entire world is facing an unprecedented crisis due to the rapidness, depth, and scope of the pandemic. The physical, mental, and social well-being of people is being adversely affected throughout the pandemic, and the national and international measures taken against it have directly or indirectly affected people's economic well-being. Movement restrictions, one of the measures to slow down the spread of the pandemic, negatively affected the supply of labor. As has been the case in the global market, Turkey has also experienced an increase in the unemployment rate and decreased incomes. ${ }^{3}$ A decrease in people's economic welfare levels in society can increase the rates of depression. ${ }^{4}$

Previous studies ${ }^{5,6}$ have revealed that the tendency to develop depression among females is higher than among males. Some studies ${ }^{6,7}$ performed during the pandemic found that females were affected more adversely compared with the males. The mother might experience emotional fluctuations during pregnancy due to the anxiety she feels for both herself and the fetus. ${ }^{8}$ The physiological and psychoso- cial changes that occur during pregnancy increase the tendency of developing depression and anxiety. In this regard, pregnant and new mothers are included in the vulnerable and high-risk group for depression. , $^{9} 10$

The female sexual response cycle can be divided into four phases: baseline, arousal (excitement), orgasm, and resolution. Regarding these phases, women might experience various sexual dysfunctions, such as lack of sexual drive and arousal, and inability to orgasm during sexual activity. It is an underestimated problem with a general prevalence between $20 \%$ and $50 \%{ }^{11}$ On the other hand, it has been demonstrated that a significant decrease in sexual activities occurs with pregnancy. Physical discomfort, fear of injuring the fetus, loss of sexual drive, physical awkwardness, painful sexual activity, and perceived lack of attraction are among the reported causes of this decrease in sexual activity during pregnancy. ${ }^{12}$

The present research aimed to investigate the depression and sexual functions of pregnant and non-pregnant women throughout the COVID-19 pandemic.

\section{Methods}

The present is a cross-sectional trial conducted from May to August, 2020 with 96 healthy pregnant and 92 nonpregnant women, totalling a sample of 188 women. Most of the pregnant and non-pregnant women whom we invited to the study did not want to participate; they wanted to be in the hospital for a shorter time because they were afraid of 
contact transmission by the doctor. In total, 188 healthy women aged between 18 and 45 years who sought care at the Gynecology and Obstetrics Outpatient Clinic of a hospital in Turkey, and who did not have any known disorder, had not received medication for chronic conditions, and voluntarily agreed to participate in our study were included. Pregnant women who had fetal or maternal problems during their pregnancy, women who had a medical history of psychiatric or sexual dysfunction, and participants who submitted incomplete questionnaires were excluded from the study. The participants read and signed the informed consent form; after that, we collected sociodemographic data from them, and applied the Beck Depression Inventory (BDI) and Arizona Sexual Experience Scale (ASEX).

Approval of the Ethics Committee was obtained (2020/514/176/9), with the project name of 2020-0507T14_43_09, from the Ministry of Health of the Republic of Turkey to conduct the relevant scientific research.

Sociodemographic data, such as age, level of schooling, occupational status, and obstetric status was obtained from the patients. They were asked whether they were pregnant or not, and, if they were, their gestational week was requested, and they were divided into three groups based on the trimester: first trimester (up until the 14th gestational week), second trimester (14th to 28th gestational weeks), and third trimester (28th to 42th gestational weeks) groups. Based on data from May 2020 from the Turkish Statistical Institute, those with a total family monthly income below the hunger limit (2,438 Turkish Lira [TL]) are considered the lower-income class, those below the poverty line (7,942 TL), the middle-income class, and those with a higher income ( $>$ 7,942 TL), the upper-income class. Regarding loss of income during the pandemic, the participants were examined in 3 groups:, those who had no income loss, those who lost up to $50 \%$ of their income, and those who lost more than $50 \%$ of their income.

The BDI was developed to measure the risk of depression, the level of the depressive symptoms, and the fluctuation in the severity of depression among adults. It is a self-administered questionnaire developed by Beck et al. ${ }^{13}$, which consists of 21 items. The items of the scale are scored from 0 and 3 points. Higher scores indicate greater symptom severity. In those diagnosed with depression, scores of between 0 and 13 indicate minimal depression, from 14 to 19 , mild depression, from 20 to 28, moderate depression and, from 29 to 63 , severe depression. ${ }^{14}$ The validity and reliability study of the Turkish adaptation of the questionnaire was performed by Hisli. $^{15}$

The Arizona Sexual Experience Scale (ASEX), which has been developed by McGahuey et al. ${ }^{16}$ to briefly and efficiently screen and identify the problems experienced by patients in their sexual life, is a five-item rating scale that measures sexual drive, arousal, vaginal lubrication/penile erection, ability to have an orgasm, and satisfaction from orgasm; and it also has separate questionnaires specific to male and female subjects. We used the female form (questionnaire detailed to female patients) in the present study. The total score ranges from 5 to 30 , and lower scores manifest that the sexual response is strong, easy, and satisfying, whereas higher scores display sexual dysfunction. The higher the scores, the more sexual dysfunction there is. ${ }^{16}$ Based on the ASEX scores, the participants were included in the healthy group (scores from 0 to 10 ), the group with moderate sexual disorder (scores from 11 to 17), and the group with severe sexual disorder (scores $\geq 18$ ). The validity and reliability of the Turkish adaptation of the ASEX have been tested among patients with renal failure. ${ }^{17}$

For the categorical values, $p$-values were calculated using the Chi-squared test. For the continuous variables, the $p$-values were calculated using the Mann Whitney U test the and Kruskall Wallis test. Multivariable logistic regressions were used to calculate odds ratios (ORs) and 95\% confidence intervals (95\%CIs) for the associations between sexual dysfunction and depressive symptoms. Potential a priori confounders (such as, age, occupational status, and parity) were included in the models. All statistical analyses were performed using The Statistical Package for the Social Sciences (IBM SPSS Statistics for Windows, IBM Corp., Armonk, NY, United States) software, version 25.0.

\section{Results}

The mean age of the sample was $30.1 \pm 6.4$ years. The demographics of the participants are presented in - Table 1.

In the univariate analysis of the factors affecting the presence of depression among the participants, severe depression was significantly more prevalent among those who were unemployed compared with the other groups. Besides, as the level of income decreases, the percentage of mild or moderate depression increases significantly $(p=0.046)$ (-Table 2).

In the univariate analysis of the BDI scores of the participants, they were significantly higher among those who were unemployed (mean $=13.8$ ) compared with those working in the public sector (mean=9.5) $(p<0.001)$. We also found that, as the level of economic income decreases, depression scores increase significantly ( $p=0.009$ ). The BDI score (mean $=13.9$ ) was significantly higher among the participants who lost their income during the pandemic compared with those who did not experienced income loss (mean=11.4) $(p=0.001)$. Furthermore, the BDI scores (mean $=14.0)$ of the patients whose relatives were diagnosed with COVID-19 was significantly higher than the scores of those whose relatives were not diagnosed $(p=0.013$ ) ( - Table 3 ).

We found that the rate of severe sexual disorder among pregnant women was significantly higher than that of the nonpregnant women $(p=0.006)$. On the other hand, the percentage of moderate sexual dysfunction was significantly higher among multiparous women $(p=0.016)$. When the participants were categorized based on their depression status, moderate sexual dysfunction was determined to be high in patients with mild depressive symptoms, whereas the rate of severe sexual dysfunction was found to be high in those with severe depressive symptoms $(p=0.008)$ ( $~-$ Table 4 ).

According to the univariate analysis, ASEX score decreases significantly as the level of schooling increases. 
Table 1 Demographics of the study participants

\begin{tabular}{|c|c|c|c|}
\hline Age (years) & & $\begin{array}{l}\text { Mean (standard } \\
\text { deviation): } 30.1 \text { (6.4) }\end{array}$ & $\begin{array}{l}\text { Median } \\
\text { (range): } 29.0 \\
(18.0-45.0)\end{array}$ \\
\hline & & $n$ & $\%$ \\
\hline \multirow[t]{3}{*}{ Level of schooling } & Primary school graduate & 23 & $12.2 \%$ \\
\hline & High school graduate & 68 & $36.2 \%$ \\
\hline & University graduate or higher & 97 & $51.6 \%$ \\
\hline \multirow[t]{3}{*}{ Occupational status } & Unemployed & 100 & $53.2 \%$ \\
\hline & Working in the public sector & 57 & $30.3 \%$ \\
\hline & Working in the private sector & 31 & $16.5 \%$ \\
\hline \multirow[t]{3}{*}{ Level of income } & Low & 17 & $9.0 \%$ \\
\hline & Medium & 110 & $58.5 \%$ \\
\hline & High & 61 & $32.4 \%$ \\
\hline \multirow[t]{2}{*}{ Pregnancy } & Absent & 92 & $48.9 \%$ \\
\hline & Present & 96 & $51.1 \%$ \\
\hline \multirow[t]{3}{*}{ Trimester of pregnancy } & First & 20 & $20.8 \%$ \\
\hline & Second & 58 & $60.4 \%$ \\
\hline & Third & 18 & $18.8 \%$ \\
\hline \multirow[t]{2}{*}{ Parity } & Nulliparous & 70 & $37.2 \%$ \\
\hline & Multiparous & 118 & $62.8 \%$ \\
\hline \multirow[t]{3}{*}{ Type of delivery } & Nulliparous & 70 & $37.2 \%$ \\
\hline & Cesarean & 69 & $36.7 \%$ \\
\hline & Vaginal & 49 & $26.1 \%$ \\
\hline Total & & 188 & $100.0 \%$ \\
\hline
\end{tabular}

Moreover, the ASEX score was higher among those who were unemployed. As the level of economic income decreases, the ASEX score increases significantly. We found that as the loss of income rose during the COVID-19 pandemic, the ASEX score also rose significantly. In addition to that, as depressive symptoms increased, the ASEX score increased as well ( $p=0.005)$ (-Table 5).

When the factors affecting sexual dysfunction in women are analyzed by the multivariate analysis, odds ratio increase was found 1.18 times (95\% CI 1.07-1.31), corresponding to each unit increase of age. Compared with those without depressive symptoms, the risk of sexual dysfunction in mildly-depressed patients increased 4.31 times (95\% CI: 1.57 to 11.82 ), while this rate was of 5.57 (95\%CI: 1.42 to 21.81) among participants with moderate/severe depression. The risk of sexual dysfunction increased 6.40 times (95\%CI: 2.09 to 19.54 ) among unemployed patients compared with those employed in the private sector. Moreover, there was an increase of 6.20 in the OR (95\% CI 2.15-17.90) among pregnant women compared with non-pregnant women (-Table 6 ).

When the correlation analysis was performed between the ASEX and BDI scores regarding the pregnancy status, a slightly positive significant correlation was found among pregnant women $(r=0.365 ; p<0.001)$.

\section{Discussion}

The expectant mother may experience emotional fluctuations throughout pregnancy because she is concerned about herself and the fetus. ${ }^{18}$ Depression, which may be experienced during pregnancy, may lead to maternal and fetal complications. $^{8}$ The stress experienced throughout the pregnancy might trigger preterm labor through the activation of the pituitary and adrenal axis, and is also a risk factor for gestational hypertension and preeclampsia. ${ }^{8,19}$ Previous researches have reported that the prevalence of depression during pregnancy ranges from $12 \%$ to $36 \%{ }^{20}$ In the present study, we found that $42.7 \%$ of pregnant women had mild symptoms of depression throughout the pandemic, whereas $21 \%$ had moderetely-severe symptoms of depression. Similarly, depression rates in non-pregnant women were found to be significantly higher than studies conducted before the pandemic. In studies of depression in female university students in Turkey prevalence of ranges from $9.2 \%$ to $35.2 \%$, in other countries between $18.5 \%$ and $52.6 \%$ $(14 a-14 c){ }^{6,21,22}$ In the present study, we found that $44.6 \%$ of non-pregnant women had mild symptoms of depression throughout the pandemic, whereas $22 \%$ had moderate/ severe symptoms. A study ${ }^{23}$ performed in Turkey during the pandemic reported that it has a considerable impact 
Table 2 Factors impacting depression among the study participants

\begin{tabular}{|c|c|c|c|c|c|c|c|c|}
\hline & & \multicolumn{2}{|c|}{ Healthy } & \multicolumn{2}{|c|}{$\begin{array}{l}\text { Mildly } \\
\text { depressed }\end{array}$} & \multicolumn{3}{|c|}{$\begin{array}{l}\text { Moderately/ } \\
\text { severely } \\
\text { depressed }\end{array}$} \\
\hline & & $n$ & $\%$ & $n$ & $\%$ & $n$ & $\%$ & $p$-value \\
\hline \multirow[t]{3}{*}{ Level of schooling } & Primary school graduate & 5 & $21.7 \%$ & 8 & $34.8 \%$ & 10 & $43.5 \%$ & 0.115 \\
\hline & High school graduate & 21 & $30.9 \%$ & 33 & $48.5 \%$ & 14 & $20.6 \%$ & \\
\hline & University graduate or higher & 37 & $38.1 \%$ & 41 & $42.3 \%$ & 19 & $19.6 \%$ & \\
\hline \multirow[t]{3}{*}{ Occupational status } & Unemployed & 25 & $25.0 \%$ & 45 & $45.0 \%$ & 30 & $30.0 \%$ & 0.003 \\
\hline & Working in the public sector & 30 & $52.6 \%$ & 20 & $35.1 \%$ & 7 & $12.3 \%$ & \\
\hline & Working in the private sector & 8 & $25.8 \%$ & 17 & $54.8 \%$ & 6 & $19.4 \%$ & \\
\hline \multirow[t]{3}{*}{ Level of income } & Low & 3 & $17.6 \%$ & 7 & $41.2 \%$ & 7 & $41.2 \%$ & 0.046 \\
\hline & Medium & 34 & $30.9 \%$ & 47 & $42.7 \%$ & 29 & $26.4 \%$ & \\
\hline & High & 26 & $42.6 \%$ & 28 & $45.9 \%$ & 7 & $11.5 \%$ & \\
\hline \multirow[t]{3}{*}{ Loss of income during the pandemic } & No & 46 & $40.7 \%$ & 46 & $40.7 \%$ & 21 & $18.6 \%$ & 0.124 \\
\hline & $\leq 50 \%$ & 9 & $22.5 \%$ & 19 & $47.5 \%$ & 12 & $30.0 \%$ & \\
\hline & $>50 \%$ & 8 & $22.9 \%$ & 17 & $48.6 \%$ & 10 & $28.6 \%$ & \\
\hline \multirow[t]{2}{*}{ Pregnancy } & Absent & 29 & $31.5 \%$ & 41 & $44.6 \%$ & 22 & $23.9 \%$ & 0.846 \\
\hline & Present & 34 & $35.4 \%$ & 41 & $42.7 \%$ & 21 & $21.9 \%$ & \\
\hline \multirow[t]{3}{*}{ Trimester of pregnancy } & First & 10 & $50.0 \%$ & 7 & $35.0 \%$ & 3 & $15.0 \%$ & 0.097 \\
\hline & Second & 22 & $37.9 \%$ & 25 & $43.1 \%$ & 11 & $19.0 \%$ & \\
\hline & Third & 2 & $11.1 \%$ & 9 & $50.0 \%$ & 7 & $38.9 \%$ & \\
\hline \multirow[t]{2}{*}{ Parity } & Nulliparous & 24 & $34.3 \%$ & 31 & $44.3 \%$ & 15 & $21.4 \%$ & 0.936 \\
\hline & Multiparous & 39 & $33.1 \%$ & 51 & $43.2 \%$ & 28 & $23.7 \%$ & \\
\hline \multirow[t]{2}{*}{ Type of delivery } & Cesarean & 24 & $34.8 \%$ & 29 & $42.0 \%$ & 16 & $23.2 \%$ & 0.986 \\
\hline & Vaginal & 15 & $30.6 \%$ & 22 & $44.9 \%$ & 12 & $24.5 \%$ & \\
\hline \multirow[t]{2}{*}{ Relative infected with COVID-19 } & No & 56 & $36.8 \%$ & 65 & $42.8 \%$ & 31 & $20.4 \%$ & 0.087 \\
\hline & Yes & 7 & $19.4 \%$ & 17 & $47.2 \%$ & 12 & $33.3 \%$ & \\
\hline
\end{tabular}

on the levels of depression and anxiety of pregnant women. In a multi-center cross-sectional study ${ }^{24}$ performed in China comparing the mental state of pregnant women before and after the declaration of the COVID-19 pandemic, the authors reported that pregnant women who were examined after the announcement of the COVID-19 outbreak had significantly higher levels of anxiety and symptoms of depression.

Previous studies ${ }^{25,26}$ have suggested that individuals who are in the lower socioeconomic class have a higher rate of mental disorders such as depression compared with individuals in middle and upper socioeconomic classes. Upon reviewing the literature, we could not detect one study that revealed a correlation between depression and parameters such as economic status and income loss during the COVID-19 pandemic. In the present study, the depression scores were significantly higher among the group with lower economic status. Likewise, the BDI score was significantly higher among patients who lost their income during the pandemic. The depression scores were significantly higher among females whose relatives have been infected with COVID-19.
The present study has demonstrated that the depression scores increased among women during the pandemic, which is in line with reports in the literature. ${ }^{15,16}$ In the present study, we found that pregnant and non-pregnant women are adversely affected in a similar manner; on the other hand, the study suggests that circumstances such as being in the lowincome class, experiencing loss of income, and having relatives infected with COVID-19 may increase the risk of developing depression.

Sexual life is one of the factors that affect the general health status and quality of life of women. Sexual dysfunction is a multifactorial problem influenced by various biological, psychological, and environmental factors. ${ }^{27}$ It has been suggested ${ }^{28}$ that sexual dysfunction is a common problem that increases with age and impacts $30 \%$ to $50 \%$ of women. Women who have an ASEX score $\geq 11$ are considered to have sexual dysfunction. In a study ${ }^{29}$ comparing pregnant and non-pregnant women in Turkey before the pandemic, the authors found high ASEX scores in 55.6\% of pregnant women and in $23.2 \%$ of non-pregnant women. In the present study the rate of sexual dysfunction 
Table 3 Factors impacting the score of Beck Depression Inventory

\begin{tabular}{|c|c|c|c|c|c|c|c|}
\hline & & Mean & $\begin{array}{l}\text { standard } \\
\text { deviation }\end{array}$ & Median & $\begin{array}{l}\text { First } \\
\text { quartile }\end{array}$ & $\begin{array}{l}\text { Third } \\
\text { quartile }\end{array}$ & $p$-value \\
\hline \multirow[t]{3}{*}{ Level of schooling } & Primary school graduate & 15.4 & 7.8 & 14.0 & 10.0 & 19.0 & 0.080 \\
\hline & High school graduate & 12.3 & 5.4 & 12.0 & 8.0 & 16.0 & \\
\hline & University graduate or higher & 11.6 & 6.2 & 11.0 & 8.0 & 15.0 & \\
\hline \multirow[t]{3}{*}{ Occupational status } & Unemployed & 13.8 & 6.2 & 13.0 & 9.5 & 18.0 & $<0.001$ \\
\hline & Working in the public sector & 9.5 & 6.0 & 9.0 & 5.0 & 12.0 & \\
\hline & Working in the private sector & 12.9 & 5.2 & 13.0 & 8.0 & 16.0 & \\
\hline \multirow[t]{3}{*}{ Level of income } & Low & 15.3 & 4.8 & 17.0 & 13.0 & 18.0 & 0.009 \\
\hline & Medium & 12.7 & 6.6 & 12.0 & 8.0 & 17.0 & \\
\hline & High & 10.9 & 5.6 & 11.0 & 7.0 & 14.0 & \\
\hline \multirow{2}{*}{$\begin{array}{l}\text { Loss of income during } \\
\text { the pandemic }\end{array}$} & No & 11.4 & 6.4 & 11.0 & 7.0 & 14.0 & 0.001 \\
\hline & Yes & 13.9 & 5.8 & 14.0 & 10.0 & 18.0 & \\
\hline \multirow[t]{2}{*}{ Pregnancy } & Absent & 12.5 & 6.2 & 12.0 & 8.0 & 17.0 & 0.389 \\
\hline & Present & 12.1 & 6.3 & 11.0 & 7.5 & 16.0 & \\
\hline \multirow[t]{3}{*}{ Trimester of pregnancy } & First & 11.1 & 6.4 & 10.0 & 7.0 & 15.0 & 0.081 \\
\hline & Second & 11.9 & 6.7 & 10.0 & 7.0 & 14.0 & \\
\hline & Third & 14.1 & 4.7 & 14.5 & 11.0 & 17.0 & \\
\hline \multirow[t]{2}{*}{ Parity } & Nulliparous & 12.4 & 6.3 & 11.0 & 8.0 & 14.0 & 0.654 \\
\hline & Multiparous & 12.3 & 6.2 & 12.0 & 8.0 & 17.0 & \\
\hline \multirow[t]{2}{*}{ Type of delivery } & Cesarean & 12.0 & 5.8 & 13.0 & 8.0 & 16.0 & 0.888 \\
\hline & Vaginal & 12.7 & 6.8 & 12.0 & 8.0 & 18.0 & \\
\hline \multirow{2}{*}{$\begin{array}{l}\text { Relative infected } \\
\text { with COVID-19 }\end{array}$} & No & 11.9 & 6.4 & 11.0 & 8.0 & 16.0 & 0.013 \\
\hline & Yes & 14.0 & 5.3 & 15.0 & 11.5 & 18.0 & \\
\hline
\end{tabular}

during the pandemic was of $83.3 \%$ among pregnant women, and of $75 \%$ among non-pregnant women. This situation indicated that the sexual lives of all women were negatively affected throughout the pandemic. A significantly higher rate of sexual dysfunction was also detected among pregnant women in the present study, and the OR was 6.2, which is in line with previous studies. $^{29,30}$

It is well documented that the level of socioeconomic wellbeing impacts sexuality. Previous studies ${ }^{31,32}$ have reported that sexual dysfunction was more prevalent among women with a lower economic status. Similarly, in the present study, sexual dysfunction was significantly higher among women in the lower-income class and among those who lost their income during the pandemic. The risk of sexual dysfunction among unemployed women is 6.40 times higher than that of employed women. One study ${ }^{33}$ demonstrated that sexual dysfunction is less common among women with higher levels of schooling. Likewise, the results of the present study support the aforementioned finding as well the fact that, as the level of schooling increases, the prevalence of sexual dysfunction decreases significantly.

Previous studies ${ }^{34-37}$ have suggested that the previous number of births and the type of delivery do not impact the sexual function. In the present study, similar results were found when the ASEX scores were analyzed.

It has been claimed ${ }^{38}$ that people under restriction have a high tendency to develop depression and anxiety, and that sexual intercourse while under restriction is a protective factor against depression. One study ${ }^{39}$ found that several women who were using short-acting reversible contraception (SARC) discontinued their contraceptive method during the pandemic but continued to engage in sexual activity and had unplanned pregnancies. The BDI and ASEX scores were also observed in parallel in the present study (-Tables $\mathbf{3 , 4}$ ), and The BDI scores were significantly higher among women with sexual dysfunction.

This study has some limitations; Firstly, it is a crosssectional trial and the long-term effects are unknown. Secondly, the study compared slightly different women in the same period, not different periods when the same women were pregnant and not pregnant. Finally, the negative impact of the pandemic detected among the participants may have been milder than the impact felt by women in other parts of Turkey, since the district where the present study was performed was considered a low-risk area for infection by SARS-CoV2. 
The Impact of the COVID-19 Pandemic on Depression and Sexual Function Denizli et al. 771

Table 4 Factors impacting sexual dysfunction

\begin{tabular}{|c|c|c|c|c|c|c|c|c|}
\hline & & \multicolumn{2}{|c|}{ Normal } & \multicolumn{2}{|c|}{$\begin{array}{l}\text { Moderate } \\
\text { sexual } \\
\text { dysfunction }\end{array}$} & \multicolumn{2}{|c|}{$\begin{array}{l}\text { Severe } \\
\text { sexual } \\
\text { dysfunction }\end{array}$} & \multirow[b]{2}{*}{$p$-value } \\
\hline & & $n$ & $\%$ & $n$ & $\%$ & $n$ & $\%$ & \\
\hline \multirow[t]{3}{*}{ Level of schooling } & Primary school graduate & 1 & $4.3 \%$ & 14 & $60.9 \%$ & 8 & $34.8 \%$ & 0.145 \\
\hline & High school graduate & 14 & $20.6 \%$ & 40 & $58.8 \%$ & 14 & $20.6 \%$ & \\
\hline & University graduate or higher & 24 & $24.7 \%$ & 57 & $58.8 \%$ & 16 & $16.5 \%$ & \\
\hline \multirow[t]{3}{*}{ Occupational status } & Unemployed & 14 & $14.0 \%$ & 62 & $62.0 \%$ & 24 & $24.0 \%$ & 0.088 \\
\hline & Working in the public sector & 14 & $24.6 \%$ & 34 & $59.6 \%$ & 9 & $15.8 \%$ & \\
\hline & Working in the private sector & 11 & $35.5 \%$ & 15 & $48.4 \%$ & 5 & $16.1 \%$ & \\
\hline \multirow[t]{3}{*}{ Level of income } & Low & 0 & $0.0 \%$ & 12 & $70.6 \%$ & 5 & $29.4 \%$ & 0.101 \\
\hline & Medium & 21 & $19.1 \%$ & 66 & $60.0 \%$ & 23 & $20.9 \%$ & \\
\hline & High & 18 & $29.5 \%$ & 33 & $54.1 \%$ & 10 & $16.4 \%$ & \\
\hline \multirow[t]{2}{*}{ Loss of income during the pandemic } & No & 29 & $25.7 \%$ & 63 & $55.8 \%$ & 21 & $18.6 \%$ & 0.123 \\
\hline & Yes & 10 & $13.3 \%$ & 48 & $64.0 \%$ & 17 & $22.7 \%$ & \\
\hline \multirow[t]{2}{*}{ Pregnancy } & Absent & 23 & $25.0 \%$ & 59 & $64.1 \%$ & 10 & $10.9 \%$ & 0.006 \\
\hline & Present & 16 & $16.7 \%$ & 52 & $54.2 \%$ & 28 & $29.2 \%$ & \\
\hline \multirow[t]{3}{*}{ Trimester of pregnancy } & First & 4 & $20.0 \%$ & 12 & $60.0 \%$ & 4 & $20.0 \%$ & 0.579 \\
\hline & Second & 11 & $19.0 \%$ & 29 & $50.0 \%$ & 18 & $31.0 \%$ & \\
\hline & Third & 1 & $5.6 \%$ & 11 & $61.1 \%$ & 6 & $33.3 \%$ & \\
\hline \multirow[t]{2}{*}{ Parity } & Nulliparous & 22 & $31.4 \%$ & 34 & $48.6 \%$ & 14 & $20.0 \%$ & 0.016 \\
\hline & Multiparous & 17 & $14.4 \%$ & 77 & $65.3 \%$ & 24 & $20.3 \%$ & \\
\hline \multirow[t]{2}{*}{ Type of delivery } & Cesarean & 14 & $20.3 \%$ & 43 & $62.3 \%$ & 12 & $17.4 \%$ & 0.018 \\
\hline & Vaginal & 3 & $6.1 \%$ & 34 & $69.4 \%$ & 12 & $24.5 \%$ & \\
\hline \multirow[t]{2}{*}{ Relative infected with COVID-19 } & No & 32 & $21.1 \%$ & 88 & $57.9 \%$ & 32 & $21.1 \%$ & 0.783 \\
\hline & Yes & 7 & $19.4 \%$ & 23 & $63.9 \%$ & 6 & $16.7 \%$ & \\
\hline \multirow[t]{3}{*}{ Depression } & Normal & 20 & $31.7 \%$ & 29 & $46.0 \%$ & 14 & $22.2 \%$ & 0.008 \\
\hline & Mildly depressed & 15 & $18.3 \%$ & 56 & $68.3 \%$ & 11 & $13.4 \%$ & \\
\hline & Moderately/severely depressed & 4 & $9.3 \%$ & 26 & $60.5 \%$ & 13 & $30.2 \%$ & \\
\hline
\end{tabular}

Table 5 Factors impacting the Arizona Sexual Experience Scale

\begin{tabular}{|c|c|c|c|c|c|c|c|}
\hline & & \multicolumn{6}{|c|}{ Arizona Sexual Experience Scale } \\
\hline & & Mean & $\begin{array}{l}\text { Standard } \\
\text { deviation }\end{array}$ & Median & $\begin{array}{l}\text { First } \\
\text { quartile }\end{array}$ & $\begin{array}{l}\text { Third } \\
\text { quartile }\end{array}$ & $p$-value \\
\hline \multirow[t]{3}{*}{ Level of schooling } & Primary school graduate & 16.2 & 3.3 & 15.0 & 14.0 & 19.0 & 0.034 \\
\hline & High school graduate & 14.4 & 4.1 & 14.0 & 12.0 & 17.0 & \\
\hline & University graduate or higher & 13.8 & 3.6 & 14.0 & 11.0 & 17.0 & \\
\hline \multirow[t]{3}{*}{ Occupational status } & Unemployed & 14.9 & 3.6 & 15.0 & 13.0 & 17.0 & 0.032 \\
\hline & Working in the public sector & 13.8 & 3.9 & 13.0 & 11.0 & 15.0 & \\
\hline & Working in the private sector & 13.4 & 4.1 & 14.0 & 10.0 & 16.0 & \\
\hline \multirow[t]{3}{*}{ Level of income } & Low & 15.9 & 2.6 & 16.0 & 15.0 & 18.0 & 0.040 \\
\hline & Medium & 14.4 & 3.9 & 14.0 & 12.0 & 17.0 & \\
\hline & High & 13.7 & 3.9 & 14.0 & 10.0 & 15.0 & \\
\hline \multirow{4}{*}{$\begin{array}{l}\text { Loss of income } \\
\text { during pandemic }\end{array}$} & No & 13.8 & 3.8 & 14.0 & 10.0 & 16.0 & 0.019 \\
\hline & $\leq 50 \%$ & 14.6 & 4.1 & 15.0 & 13.0 & 16.0 & \\
\hline & $>50 \%$ & 15.7 & 3.3 & 16.0 & 13.0 & 18.0 & \\
\hline & & & & & & & ontinued) \\
\hline
\end{tabular}


772 The Impact of the COVID-19 Pandemic on Depression and Sexual Function Denizli et al.

Table 5 (Continued)

\begin{tabular}{|c|c|c|c|c|c|c|c|}
\hline & & \multicolumn{6}{|c|}{ Arizona Sexual Experience Scale } \\
\hline & & Mean & $\begin{array}{l}\text { Standard } \\
\text { deviation }\end{array}$ & Median & $\begin{array}{l}\text { First } \\
\text { quartile }\end{array}$ & $\begin{array}{l}\text { Third } \\
\text { quartile }\end{array}$ & $p$-value \\
\hline \multirow[t]{2}{*}{$\overline{\text { Pregnancy }}$} & Absent & 13.3 & 3.3 & 13.0 & 10.5 & 15.0 & $<0.001$ \\
\hline & Present & 15.2 & 4.0 & 15.0 & 13.0 & 18.0 & \\
\hline \multirow[t]{3}{*}{ Trimester of pregnancy } & First & 14.6 & 3.8 & 15.0 & 13.0 & 17.0 & 0.260 \\
\hline & Second & 15.1 & 4.4 & 15.0 & 12.0 & 18.0 & \\
\hline & Third & 16.4 & 2.7 & 17.0 & 15.0 & 19.0 & \\
\hline \multirow[t]{2}{*}{ Parity } & Nulliparous & 13.8 & 4.1 & 14.0 & 10.0 & 17.0 & 0.064 \\
\hline & Multiparous & 14.6 & 3.6 & 15.0 & 13.0 & 17.0 & \\
\hline \multirow[t]{3}{*}{ Type of delivery } & Nulliparous & 13.8 & 4.1 & 14.0 & 10.0 & 17.0 & 0.098 \\
\hline & Cesarean & 14.3 & 4.0 & 15.0 & 12.0 & 17.0 & \\
\hline & Vaginal & 15.0 & 3.1 & 15.0 & 13.0 & 17.0 & \\
\hline \multirow{2}{*}{$\begin{array}{l}\text { Relative infected } \\
\text { with COVID-19 }\end{array}$} & No & 14.3 & 3.8 & 14.0 & 12.0 & 17.0 & 0.888 \\
\hline & Yes & 14.2 & 3.9 & 14.0 & 12.0 & 16.0 & \\
\hline \multirow[t]{3}{*}{ Depression } & Normal & 13.7 & 4.4 & 14.0 & 10.0 & 17.0 & 0.005 \\
\hline & Mildly depressed & 14.0 & 3.1 & 14.0 & 12.0 & 15.0 & \\
\hline & Moderately/severely depressed & 15.8 & 3.8 & 16.0 & 14.0 & 18.0 & \\
\hline
\end{tabular}

Table 6 Multivariate analysis of the factors impacting sexual dysfunction

\begin{tabular}{|c|c|c|c|c|c|c|c|}
\hline & \multirow[t]{2}{*}{ B } & \multirow[t]{2}{*}{ SE } & \multirow[t]{2}{*}{ Wald test } & \multirow[t]{2}{*}{ p-value } & \multirow[t]{2}{*}{ Odds Ratio } & \multicolumn{2}{|c|}{$\begin{array}{l}\text { 95\% confidence } \\
\text { interval }\end{array}$} \\
\hline & & & & & & Lower & $\overline{\text { Upper }}$ \\
\hline Age (years) & 0.173 & 0.051 & 11.598 & 0.001 & 1.189 & 1.076 & 1.313 \\
\hline Healthy & & & 10.153 & 0.006 & & & \\
\hline Mildly depressed & 1.462 & 0.514 & 8.084 & 0.004 & 4.317 & 1.575 & 11.829 \\
\hline Moderately/severely depressed & 1.718 & 0.696 & 6.089 & 0.014 & 5.573 & 1.424 & 21.812 \\
\hline Working in the private sector & & & 10.696 & 0.005 & & & \\
\hline Unemployed & 1.857 & 0.569 & 10.634 & 0.001 & 6.402 & 2.098 & 19.543 \\
\hline Working in the public sector & 1.217 & 0.635 & 3.670 & 0.055 & 3.377 & .972 & 11.731 \\
\hline Pregnant & 1.826 & 0.540 & 11.421 & 0.001 & 6.209 & 2.153 & 17.905 \\
\hline Multiparous & 0.267 & 0.539 & 0.245 & 0.620 & 1.306 & 0.454 & 3.758 \\
\hline Loss of income & 1.040 & 0.545 & 3.647 & 0.056 & 2.830 & 0.973 & 8.230 \\
\hline
\end{tabular}

$\mathrm{B}=$ value; $\mathrm{SE}=$ standard error.

\section{Conclusion}

In the present study, women who lost their income during the pandemic had higher rates of depression and sexual dysfunction. Upon comparing the pregnant and nonpregnant women, we found that the rates of depression were similarly higher in both groups than the before pandemic, whereas the rate of sexual dysfunction was 6.2 times (95\%CI: 2.1 to 17.9 ) higher among pregnant women. Low-income families and women have an increased risk of experiencing depression and sexual dysfunction in times of global crises, such as a pandemic.

\section{Contributions}

All authors participated in the concept and design of the present study; in the analysis and interpretation of data; in the draft or revision of the manuscript; and they have approved the manuscript as submitted. All authors are responsible for the reported research. 


\section{Ethical considerations}

All procedures performed in this study were in accordance with the ethical standards of the institutional research committee and with the 1964 Helsinki declaration and its later amendments or comparable ethical standards.

\section{Conflict of Interests}

The authors have no conflict of interests to declare.

\section{References}

1 Budak F, Korkmaz S [An overview of the COVID-19 pandemic process: the case of Turkey]. J Soc. Res Manage. 2020;(01):62-79. Doi: 10.35375/sayod.738657Turkish.

2 Ankarali H, Ankarali S, Erarslan N. COVID-19, SARS-CoV2, infectıon: current epidemiological analysis and modeling of Disease. Anatol Clin J Med Sci.. 2020;25(Suppl 1):1-22. Doi: 10.21673/ anadoluklin.707038

3 Açikgöz Ö, Günay A. The early impact of the Covid-19 pandemic on the global and Turkish economy. Turk J Med Sci. 2020;50(SI-1) 520-526. Doi: 10.3906/sag-2004-6

4 Freeman A, Tyrovolas S, Koyanagi A, Chatterji S, Leonardi M, Ayuso-Mateos JL, et al. The role of socio-economic status in depression: results from the COURAGE (aging survey in Europe). BMC Public Health. 2016;16(01):1098. Doi: 10.1186/s12889016-3638-0

5 Kuehner C. Why is depression more common among women than among men? Lancet Psychiatry. 2017;4(02):146-158. Doi: 10.1016/S2215-0366(16)30263-2

6 Richards D, Sanabria AS. Point-prevalence of depression and associated risk factors. J Psychol. 2014;148(03):305-326. Doi: 10.1080/00223980.2013.800831

7 Thapa SB, Mainali A, Schwank SE, Acharya G. Maternal mental health in the time of the COVID-19 pandemic. Acta Obstet Gynecol Scand. 2020;99(07):817-818. Doi: 10.1111/aogs.13894

8 Kim DR, Sockol LE, Sammel MD, Kelly C, Moseley M, Epperson CN. Elevated risk of adverse obstetric outcomes in pregnant women with depression. Arch Women Ment Health. 2013;16(06): 475-482. Doi: 10.1007/s00737-013-0371-x

9 López-Morales H, Del Valle MV, Canet-Juric L, Andrés ML, Galli JI, Poó F, et al. Mental health of pregnant women during the COVID19 pandemic: A longitudinal study. Psychiatry Res. 2021; 295:113567. Doi: 10.1016/j.psychres.2020.113567

10 Figueiredo B, Conde A. Anxiety and depression in women and men from early pregnancy to 3-months postpartum. Arch Women Ment Health. 2011;14(03):247-255. Doi: 10.1007/s00737-0110217-3

11 Garcia S, Moreno S, Aponte H. Prevalence of sexual dysfunction in female outpatients and personnel at a Colombian hospital: correlation with hormonal profile. J Sex Med. 2008;5(05):1208-1213. Doi: $10.1111 / \mathrm{j} .1743-6109.2007 .00718 . x$

12 Orji EO, Ogunlola IO, Fasubaa OB. Sexuality among pregnant women in South West Nigeria. J Obstet Gynaecol. 2002;22(02): 166-168. Doi: 10.1080/01443610120113319

13 Beck AT, Ward CH, Mendelson M, Mock J, Erbaugh J. An inventory for measuring depression. Arch Gen Psychiatry. 1961;4:561-571. Doi: 10.1001/archpsyc.1961.01710120031004

14 Beck AT, Steer RA, Brown GK. BDI-II: Beck Depression Inventory manual. 2nd ed. San Antonio: Psychological Corporation; 1996

15 Hisli N. [A reliability and validity study of Beck Depression Inventory in a university student sample]. Turk. J Psychol. 1989; 7(23):3-13Turkish.

16 McGahuey CA, Gelenberg AJ, Laukes CA, Moreno FA, Delgado PL, McKnight KM, et al. The Arizona sexual experience scale (Asex): reliability and validity. J Sex Marital Ther. 2000;26(01):25-40. Doi: $10.1080 / 009262300278623$
17 Soykan A. The reliability and validity of Arizona sexual experiences scale in Turkish ESRD patients undergoing hemodialysis. Int J Impot Res. 2004;16(06):531-534. Doi: 10.1038/sj.ijir.3901249

18 Kinsella MT, Monk C. Impact of maternal stress, depression and anxiety on fetal neurobehavioral development. Clin Obstet Gynecol. 2009;52(03):425-440. Doi: 10.1097/GRF.0b013e3181b52df1

19 Sandman CA, Wadhwa PD, Chicz-DeMet A, Dunkel-Schetter C, Porto M. Maternal stress, HPA activity, and fetal/infant outcome. Ann N Y Acad Sci. 1997;814:266-275. Doi: 10.1111/j.17496632.1997.tb46162.x

20 Çalik KY, Aktaş S [Depression in pregnancy: prevalence, risk factors and treatment]. Curr Approaches Psychiatry.. 2011;3 (01):142-162Turkish.

21 Burger PHM, Neumann C, Ropohl A, Paulsen F, Scholz M. Development of depression and deterioration in quality of life in German dental medical students in preclinical semesters. Ann Anat. 2016;208:183-186. Doi: 10.1016/j.aanat.2016.05.011

22 Açikgöz A, Dayi A, Binbay T. [Prevalence of depression among female university students and associated factors]. Cukurova Med J.. 2018;43(01):131-140. Doi: 10.17826/cumj.340629Turkish.

23 Durankuş F, Aksu E. Effects of the COVID-19 pandemic on anxiety and depressive symptoms in pregnant women: a preliminary study. J Matern Fetal Neonatal Med. 2020;•*:1-7. Doi: 10.1080/14767058.2020.1763946[ahead of print]

24 Wu Y, Zhang C, Liu H, Duan C, Li C, Fan J, et al. Perinatal depressive and anxiety symptoms of pregnant women along with COVID-19 outbreak in China. Am J Obstet Gynecol. 2020;223(02):240.e1-e9. Doi: 10.1016/j.ajog.2020.05.009

25 Almeida-Filho N, Lessa I, Magalhães L, Araújo MJ, Aquino E, James SA, et al. Social inequality and depressive disorders in Bahia, Brazil: interactions of gender, ethnicity, and social class. Soc Sci Med. 2004;59(07):1339-1353. Doi: 10.1016/j.socscimed.2003. 11.037

26 Kaya B. [Depression: a socio-economic and cultural perspective]. Turk J Clin Psychiatr.. 2007;10(06):11-20Turkish.

27 Salonia A, Munarriz RM, Naspro R, Nappi RE, Briganti A, Chionna $\mathrm{R}$, et al. Women's sexual dysfunction: a pathophysiological review. BJU Int. 2004;93(08):1156-1164. Doi: 10.1111/j.1464410X.2004.04796.X

28 Basson R, Althof S, Davis S, Fugl-Meyer K, Goldstein I, Leiblum S, et al. Summary of the recommendations on sexual dysfunctions in women. J Sex Med. 2004;1(01):24-34. Doi: 10.1111/j.17436109.2004.10105.x

29 Anğın AD, Özkaya E, Çetin M, Gün I, Sakin O, Ertekin LT, et al. Comparison of female sexual function and sexual function of their partners between groups of pregnant and non-pregnant women. Ginekol Pol. 2020;91(05):235-239. Doi: 10.5603/GP.2020.0062

30 Aydin M, Cayonu N, Kadihasanoglu M, Irkilata L, Atilla MK, Kendirci M. Comparison of sexual functions in pregnant and non-pregnant women. Urol J. 2015;12(05):2339-2344

31 Anees M, Batool S, Imtiaz M, Ibrahim M. Socio-economic factors affecting quality of life of Hemodialysis patients and its effects on mortality. Pak J Med Sci. 2018;34(04):811-816. Doi: 10.12669/ pjms.344.15284

32 Alp Yilmaz F, Avci D, Arzu Aba Y, Ozdilek R, Dutucu N. Sexual dysfunction in postpartum Turkish women: it's relationship with depression and some risk factors. Afr J Reprod Health. 2018;22 (04):54-63. Doi: 10.29063/ajrh2018/v22i4.6

33 Astepe BS, Köleli I. A cross-sectional study of female sexual dysfunction among Turkish pregnant and nonpregnant women: correlation with hormone profile. Eur Respir J. 2018;5(02): 258-267. Doi: 10.18621/eurj.432490

34 Acele EÖ, Karaçam Z. Sexual problems in women during the first postpartum year and related conditions. J Clin Nurs. 2012;21(78):929-937. Doi: 10.1111/j.1365-2702.2011.03882.x

35 Banaei M, Moridi A, Dashti S. Sexual dysfunction and its associated factors after delivery: longitudinal study in Iranian women. 
774 The Impact of the COVID-19 Pandemic on Depression and Sexual Function Denizli et al.

Mater Sociomed. 2018;30(03):198-203. Doi: $10.5455 /$ msm.2018.30.198-203

36 Makkii M, Yazdi NA. Sexual dysfunction during primiparous and multiparous women following vaginal delivery. Tanzan J Health Res. 2012;14(04):263-268. Doi: 10.4314/thrb.v14i4.5

37 Kahramanoglu I, Baktiroglu M, Hamzaoglu K, Kahramanoglu O, Verit FF, Yucel $\mathrm{O}$. The impact of mode of delivery on the sexual function of primiparous women: a prospective study. Arch Gynecol Obstet. 2017;295(04):907-916. Doi: 10.1007/s00404-017-4299-7
38 Mollaioli D, Sansone A, Ciocca G, Limoncin E, Colonnello E, Di Lorenzo G, et al. Benefits of sexual activity on psychological, relational, and sexual health during the COVID-19 breakout. J Sex Med. 2021;18(01):35-49. Doi: 10.1016/j.jsxm.2020.10.008

39 Caruso S, Rapisarda AMC, Minona P. Sexual activity and contraceptive use during social distancing and self-isolation in the COVID-19 pandemic. Eur J Contracept Reprod Health Care. 2020;25(06):445-448. Doi: 10.1080/13625187.2020. 1830965 